\title{
MÉTRICA, MÚSICA Y LECTURA DEL POEMA
}

\author{
Rafael Núñez Ramos
}

Universidad de Oviedo

En la integridad de su naturaleza, el verso refleja la calidad musical de cada lengua.

Navarro Tomás

La relación entre métrica y poesía es tan estrecha que la palabra «verso» con la que se nombra la unidad métrica por excelencia se puede usar en ciertos contextos como sinónimo de «poesía lírica». Sin embargo, esta relación es por lo general asumida de forma mecánica sin reparar en su importancia y significación. En mi opinión afecta a la esencia misma de la poesía lírica y está estrechamente vinculada a su origen, por no decir su efectiva condición, musical. El verso no es un ornamento, una forma proporcionada y regular de componer los enunciados, portadores principales de la significación, es más bien un sistema que se aplica a los significantes para, sin olvidar su relación de significación, destacar su condición de sonidos, potenciar sus valores musicales y descubrir en ello una capacidad de significación extraconvencional y extraconceptual que permite al poema expresar lo inex- 
presable: el sentimiento humano. Sin embargo, desde el momento en que la poesía se comunica a través del libro y la letra impresa, hace depender su condición sonora de la codificación visual y de esta manera tienden a hiperdesarrollarse los aspectos más intelectuales y reflexivos de la palabra, es decir, los menos musicales. Como titula McLuhan uno de los epígrafes de La galaxia Gutenberg, «En la página impresa se reflejó por primera vez el divorcio entre la poesía y la música». Tal divorcio se ha ido acrecentando no tanto en los creadores, aunque a veces es difícil comprender por qué son verso algunas composiciones que se presentan como tales, como en las condiciones generales de recepción que reflejan los manuales de literatura y numerosas lecturas públicas. El hecho de que numerosos poemas sirvan de letra a algunas canciones y que otras, despojadas de su música, puedan ser apreciadas como auténticos poemas ${ }^{1}$ revelan, sin embargo, la pervivencia de esta condición original de la poesía que la lectura debe preservar.

Entiendo que la métrica no es simplemente una huella de un origen en que la poesía iba acompañada de música o era cantada, es también y sobre todo la condición de una música peculiar que todavía se conserva y puede manifestarse en el acto de lectura y, al mismo tiempo, el mecanismo que pone de relieve la sonoridad de los enunciados. Todo ello expresa la manera de ser de la poesía lírica, por lo cual, si se pierde o si se difumina, nos encontraríamos ante otra forma artística o literaria de intenciones y potencialidades diferentes. Por esta razón, me propongo analizar las unidades métricas, su relación con la música y su participación en la configuración y sentido final del poema en el acto de lectura. El poema, decía Valery, es la ejecución del poema; de la misma manera que la música, sólo se produce efectivamente cuando es ejecutada por un instrumento, en este caso la voz humana. Ahora bien, no es posible establecer los caracteres de la dicción poética a partir de un análisis de diferentes lecturas, de cómo leen poesía distintas personas, pues en la ejecución intervienen factores muy particulares, entre otros la concepción, intuitiva o reflexiva, que el lector tiene de la dicción. Se trata, entonces, de legitimar una concepción a partir de postulados teóricos para definir los caracteres de la lectura que más le convienen. La verificación empírica podría hacerse acumulando diversas lecturas, analizándolas de acuerdo con la teoría propuesta y, finalmente,

1 Por ejemplo, en la Colección Mitos Poesía, la editorial Grijalbo-Mondadori (Madrid, 1999) ha publicado un volumen titulado 56 boleros, recopilados por Carlos Monsiváis, para quien el género «condensa la idea de poesía personal y de apasionamiento de millones de personas» (subrayado mío). 
comprobando con los aparatos de registro y análisis las peculiaridades de unas y otras. En esta ocasión, y partiendo del postulado que atribuye a la poesía lírica una condición musical, me propongo solamente analizar las unidades métricas, su relación con las unidades musicales y con el carácter de la poesía lírica, y establecer algunas pautas para una lectura conforme con este análisis.

\section{LA SÍLABA}

La sílaba, el menor de los constituyentes de la jerarquía prosódica, en fórmula de Nespor y Vogel, 1994:79, es la unidad mínima de la lengua que el hablante puede ejecutar de una vez y que percibe intuitivamente como diferenciada en el uso. Si se le pide, por ejemplo, a alguien que hable más despacio lo hará alargando la duración de las sílabas y, en última instancia, separándolas unas de otras (ca-ta-li-na). El fonema, salvo que constituya sílaba por sí mismo, no existe aislado ni en la pronunciación ni en la audición, es decir fuera de la sílaba. La sílaba es, en definitiva, la unidad entonable (Sosa, 1999:51) y medible, y por tanto una unidad métrica y musical. En este sentido, tiene una relación directa con la música a través del canto, que puede tener una ejecución silábica, es decir hace coincidir cada sílaba del texto con una nota, o una ejecución melismática en la que varias notas convergen sobre una sílaba. Aunque el canto admite las dos posibilidades $y$, por tanto también las admite el poema cantado (no hay más que observar las partituras a las que se superpone el texto), en el poema simplemente recitado la sílaba puede considerarse como la unidad equivalente de la nota, la unidad mínima de composición que puede discriminarse de manera natural.

Sin embargo, la sílaba no tiene la plasticidad que tienen para la duración las notas musicales que pueden subdividirse en figuras (negra, corchea, semicorchea...) y adoptar las correspondientes equivalencias (una negra equivale a dos corcheas, una corchea a dos semicorcheas, etc.). A lo sumo, en algunas lenguas (como el latín y el griego) las sílabas admiten dos categorías según la duración de sus vocales nucleares: larga y breve, y sobre estas categorías se funda su métrica en la que la única equivalencia posible se plantea entre dos breves y una larga. No es el caso del castellano, aunque algunos poetas hayan tratado de imitar el sistema de las lenguas clásicas equiparando largas con tónicas y 
breves con átonas. Pero las sílabas tónicas y átonas se definen en relación al acento, categoría más compleja que no puede reducirse a la duración ni a la intensidad, como analizaremos en el próximo epígrafe. Por lo que se refiere a las sílabas, tienen una duración variable, pero en una dicción espontánea, aunque no precipitada, se sienten básicamente como equivalentes. Por esta razón, el verso clásico castellano (que es una unidad métrica artificial adoptada por la poesía) se define por el número de sus sílabas y de ahí recibe de ordinario el nombre (heptasílabo, ocotosílabo, endecasílabo, etc.).

Pero la sílaba no es una unidad de uso inmediato, no es un signo por sí mismo, es la parte resultante de descomponer fónica y acústicamente unidades más complejas, como las palabras o las frases, que sí poseen significación. En este sentido, la sílaba no es una unidad autónoma, sólo existe en otra unidad que es de naturaleza diferente (la palabra no es sólo un compuesto de sílabas). No es posible manejar sílabas fuera de las palabras, a no ser que nos situemos fuera de la lengua o en esos juegos como las sopas de letras en que las sílabas aparecen como entidades separadas, pero una vez desgajadas de palabras de la lengua que hay que tratar de recuperar para que la sílaba recupere su razón de ser. Si se profieren sílabas aisladas sin tratar de evocar las palabras que las contienen se comprueba de nuevo su falta de plasticidad: las sílabas sueltas (a-cal-ta-co-pre-lo-dei-vor-sa-ci-je) son monótonamente equivalentes en sus valores musicales (duración, altura) y arbitrariamente desiguales en su concreción fonética; concreción fonética que, en estas circunstancias, resulta anodina (es decir, insignificante). Dentro de la palabra y de la frase, la equivalencia que las sílabas tienen en abstracto se conserva parcialmente, sobre todo por la uniformización perceptiva de una duración muy aproximada, pero totalmente irregular; es esto lo que convierte a la sílaba en unidad de cómputo. Pero la equivalencia en ciertos aspectos es también el espacio de las variaciones tonales que conforman la musicalidad del lenguaje que la poesía trata de recuperar.

\section{EL ACENTO}

El acento es un fenómeno complejo que se inscribe en el interior de una sílaba pero que repercute sobre todo el segmento. Tradicionalmente, el acento se define por la mayor intensidad de determinadas sílabas, 
las tónicas, que de esta manera contrastan con las restantes, las átonas. Las sílabas tónicas son sentidas por el hablante medio como más fuertes que las otras, lo que le permite, en su caso, identificar la posición de la tilde en la representación gráfica. Este fenómeno está suficientemente arraigado en la conciencia lingüística de los usuarios como para considerarlo como un valor en sí, aunque su caracterización fonética experimental no sea muy precisa. De hecho, Martínez Celdrán (256257) observa que los experimentos modernos han puesto de relieve que el acento de intensidad es «una amalgama de hechos físicos concomitantes, pues en tal acento no sólo interviene la intensidad y el tono, sino también la cantidad e incluso diferencias de timbre» ${ }^{2}$. Pero, independientemente de los parámetros que lo determinen, se trata de un fenómeno destacable que da relieve a la sílaba y la pone en contraste con los demás. Así pues, aunque la acentuación silábica sea un fenómeno complejo de variadas consecuencias acústicas, importa destacar ahora su efecto de relieve o preeminencia de unas sílabas sobre otras, lo que lo hace equivalente a un fenómeno de intensidad y permite distinguir sílabas o golpes fuertes y débiles. Por esta razón, ambos, acento y sílaba, constituyen los factores rítmicos por excelencia.

Si entendemos por ritmo la alternancia regular en el tiempo de fenómenos equivalentes, el acento constituye la clase de equivalencia más característica en relación con la sílaba. Si la secuencia lingüística y musical puede ser caracterizada como una sucesión de golpes (notas o sílabas), el acento sirve para destacar determinados golpes y organizar la secuencia rítmicamente. Es el retorno del golpe acentuado lo que queda determinado por el compás en música y por el verso en poesía (en castellano el acento en la penúltima sílaba del verso). Pero hay una diferencia notable entre la música y la poesía: las unidades musicales no están predefinidas como acentuadas o no acentuadas, de manera que cualquier nota acepta con naturalidad su ubicación en el compás, asumiendo automáticamente el acento la que ocupa la primera posición. En poesía, en cambio, las sílabas son átonas o tónicas en el código de la lengua, están predefinidas como tales por su participación en la configuración de la palabra de la que forman parte.

Como norma general, la métrica poética asume el carácter que cada sílaba tiene en el código, es decir en la palabra convencional. En prin-

2 En experimentos que yo mismo he realizado con la ayuda de Guillermo Lorenzo hemos podido comprobar como una $a$ acentuada se percibía claramente como $o$ si se aislaba de las sílabas adyacentes, pero sonaba como $a$ en el seno de la palabra. 
cipio, un poema se lee como cualquier otro texto convencional, con total naturalidad. Sólo su disposición sobre la página altera los principios habituales de dicción. El blanco al final de la línea limita el horizonte de lo que queda por leer y dispone al lector a terminar el grupo melódico en ese punto, lo que obliga a dar relieve acentual a su penúltima sílaba. Esta convención métrica, la única sistemática, tiene una fuerza propia que, en caso de conflicto con las normas lingüísticas, se impone; es decir, la penúltima posición del verso es una posición acentuada, debe ser ocupada por una sílaba acentuada de una palabra llena o semillena; si no es así, la sílaba en cuestión recibirá de todas formas el acento. Esto no supone desplazamiento del acento (pues a efectos métricos todas las palabras a final de verso son llanas), pero sí acentuación de vocablos átonos como artículos, preposiciones, etc. Así puede verse en el cuarto de estos versos de Rubén Darío (Lo fatal), en el que la palabra por recibe acentuación y tiene el valor de dos sílabas (tónica-átona):

\footnotetext{
Ser y no saber nada, y ser sin rumbo cierto, y el temor de haber sido y un futuro terror... Y el espanto seguro de estar mañana muerto, y sufrir por la vida y por la sombra y por

lo que no conocemos y apenas sospechamos...
}

El hecho de que las sílabas estén caracterizadas como tónicas o átonas antes de insertarse en el verso implica que éste debe asumir acentos adicionales al que lo constituye en la penúltima sílaba (en el verso en cuestión también reciben acento las sílabas frir, vi y som). Estos acentos son propios de la palabra independientemente de su uso y se activan en la entonación normal con mayor o menor fuerza según su posición en la frase y en el sintagma. Pero también tienen importancia rítmica, pues suponen otros puntos de preeminencia en posiciones relacionadas con la penúltima (es decir, par o impar), de manera que constituyen un ictus complementario cuando señalan la frontera de un grupo fónico (Su aliento humo, sus relinchos fuego) o marcas de un ritmo más tenue e irregular, pero persistente, que se propaga por el resto del verso (serían, en el caso de que los haya, los acentos en segunda, cuarta (o sexta) y octava del endecasílabo, por ejemplo:Su aliento humo, sus relinchos FUEgo). Los acentos que ocupan posiciones no alineadas con la penúltima son, por lo general, de importancia menor, salvo excepciones en algún modelo de verso o en casos 
concretos de utilización premeditada. Volveremos sobre estas cuestiones al tratar del verso. Lo que importa ahora es subrayar cómo el acento fundamental (en penúltima) procede de una división artificial de las frases, pero determina fuertemente la posición de los acentos interiores que, sin embargo, no puede ser artificial, sino ajustada a la acentuación convencional de la palabra y al sentido del enunciado.

Pero el acento no es sólo la marca de una diferencia entre las sílabas, es también un factor que regula la altura de las sílabas y, en definitiva, la entonación de la frase, es decir su curva melódica, su música efectiva más allá del mecanicismo métrico-rítmico. De esta forma, se abre la posibilidad de un conflicto entre el papel rítmico del acento, que exige un relieve particular en la penúltima sílaba y por tanto una configuración tonal específica, y su papel melódico que liga las variaciones tonales al sentido de la frase. Este conflicto se relaciona con todos los problemas que plantea el final del verso que analizamos en el próximo epígrafe.

\section{LA PAUSA}

3.1. Los momentos más problemáticos del poema son los silencios; su ubicación y su duración influyen de manera decisiva en el ritmo y en la melodía, hasta el punto de que, si resultan inadecuados, pueden hacer que el primero se pierda y la segunda se transforme y desfigure. Es en el terreno de las pausas donde la doble matriz de la partitura poética (dicción natural y disposición tipográfica) transmite con más frecuencia instrucciones contradictorias que pueden poner en peligro la ejecución musical del poema. Recordemos que la premisa que manejamos como determinante de la dicción del poema es su condición musical. En música, los silencios tienen el mismo valor que las notas y pueden ocupar cualquier posición, como las notas mismas, aunque su lugar más frecuente sea al final de la pieza o de alguna parte completa. En poesía, aunque se conserva esta segunda tendencia, no se da la posibilidad de que ocupen cualquier lugar. Creo que aquí es importante recordar la unificación que para el oído tiene la duración de las sílabas: si las sílabas, aunque se perciban como idénticas, tienen distinta duración, con amplios márgenes de variación, resultará muy difícil producir y computar un silencio como una unidad alternante con las sílabas, pues se produce la tendencia de unirlo a la sílaba anterior y o 
a la siguiente si no es muy largo, y a sentirlo como un corte en el curso regular de las sílabas, si se prolonga en exceso. Aunque hubo algún intento de introducir formas de silencio en el cómputo silábico, lo cierto es que nuestra tradición literaria no contempla en absoluto la posibilidad de contar una posición del verso en cuanto ocupada por un silencio, salvo, posiblemente, el caso de los finales agudos. Ahora bien, aunque la poesía tenga dificultades para cuantificar los silencios y utilizarlos métricamente como equivalentes a las sílabas, no por ello deja de someterlos a criterios musicales. Con estos criterios es necesario considerar las tradicionales pausas en el interior o al final del verso.

3.2. Las posibles pausas en el interior de los versos, que por cierto no impiden la sinalefa, no suman sílabas en el cómputo total. Ambas circunstancias me parecen suficientes para no considerarlas como tales pausas. Juan Manuel Sosa, que apoya su punto de vista en Navarro Tomás y Canellada y Madsen, subraya cómo en el lenguaje oral (y la musicalidad de la poesía sólo se realiza oralmente) no siempre hay pausas reales delimitando los grupos melódicos. Lo que él encuentra en sus análisis son tonos de juntura, que son los movimientos con función delimitadora que aparecen al final de las secuencias (1999: 31). No se produce en estos casos una interrupción de las vibraciones vocálicas, sino retardamiento de la articulación, cambio más o menos brusco de la altura musical y depresión de la intensidad, por decirlo con las palabras de Navarro Tomás que evoca el propio Sosa. No se trata, pues, de negar la existencia de un fenómeno peculiar en estas posiciones; pero este fenómeno no puede ser una interrupción que haga perder el sentido cuantitativo del verso como unidad de sílabas sucesivas. Si en medio del endecasílabo, por ejemplo, se hace una pausa prolongada, en vez de percibirse una secuencia de once sílabas, se percibirán dos de cinco y seis, o de siete y cuatro, $u$ otra posibilidad cualquiera, con la consecuente pérdida del ritmo ${ }^{3}$. Como la palabra «pausa» significa claramente interrupción, no resulta conveniente para designar este fenómeno, aun en el caso de que sea tolerable un brevísimo silencio que no afecte al cómputo silábico. Por otra parte este fenómeno está ligado al sentido de los enunciados y se manifiesta en la escritura a través de la puntuación. En la lectura en voz alta de poe-

3 Se podría argumentar que se trata de una ruptura voluntaria del ritmo para producir determinados efectos. Sin descartar esta interpretación en unos pocos casos, que, sin embargo, deberían recibir una explicación ad hoc fuertemente motivada, no me parece la más acertada en la medida en que los versos conservan en estos casos el número de sílabas del modelo adoptado y, por tanto, pueden recibir una ejecución musical sin violencia. 
sía la puntuación ejerce una presión, sobre todo en fases de aprendizaje, que lleva a un alargamiento excesivo de una interrupción que, de producirse, apenas debe ser notada para conservar el ritmo.

3.3. Todavía más problemática es la pausa al final del verso. En principio parece imprescindible para constituir al verso como secuencia silábica. El silencio, señalado por el corte brusco de la línea, sería la impresión indicativa del final de una secuencia de determinado número de sílabas y del comienzo de la siguiente. Sólo reconoceríamos un octosílabo, pongamos por caso, en la medida en que podemos separar sus ocho sílabas de las ocho del verso anterior y de las ocho del siguiente. El silencio sería el elemento de esa separación. Sin embargo, una pausa notable y sistemática en esa posición destruiría el flujo melódico natural y convertiría al poema recitado en una especie de letanía mecánica, lo que en el mundillo del teatro se conoce con el expresivo nombre de «rengloneo». El encabalgamiento es el fenómeno métrico que pone de relieve esta contradicción, pero el problema, en mi opinión, afecta a todos los versos. El problema del encabalgamiento estriba en que la dicción que se atiene a la sintaxis rompe el ritmo, la impresión de una sucesión de segmentos regulares con respecto al número de sílabas, mientras que la dicción que conserva la pausa destruye la entonación natural y, por ende, la melodía del poema. Isabel Paraíso afirma que lo que ocurre es que «disminuye mucho la pausa versal (aunque no se suprima en las buenas dicciones), y como compensación se produce un tonema inesperado, de suspensión, en el final del verso cuyo sentido no está completo» (2000: 99). En mi opinión, esta solución debe generalizarse. La pausa de final de verso, si se produce en la dicción musicalmente adecuada, ha de ser muy breve y, en todo caso, irrelevante desde el punto de vista del cómputo de unidades rítmicas (sílabas o silencios). Recordemos que tampoco en música se hace pausa después de cada compás, el cual determina únicamente la acentuación y el número de unidades. Lo mismo puede decirse del verso; el tipo elegido (octosílabo, eneasílabo, etc.) impone un acento fundamental en la penúltima sílaba y otros secundarios. Pues bien, el acento fundamental va seguido de una depresión o un tonema de suspensión que afectaría a la última sílaba inacentuada; sílaba que no se dice, pues no existe, pero se siente y se cuenta en el caso de los finales agudos, o que es el resultado de dos sílabas reales en el caso de los finales esdrújulos.

Este problema del final de verso en palabra aguda o esdrújula puede ser interesante para aclarar la cuestión de la pausa. Esteban Torre le 
dedica un amplio y documentadísimo capítulo en un libro reciente. (2000: 51-77). En él analiza en profundidad los argumentos que Domínguez Caparrós (1993: 72-73) ofrece para explicar el cómputo de ambos como llanos y subraya como especialmente determinante la presencia de la pausa de final de verso, junto con la concepción del verso como unidad rítmica y el reconocimiento del carácter culminante de la última sílaba acentuada. En mi opinión, la unidad rítmica del verso queda preservada con el relieve característico de la penúltima sílaba o axis rítmico, que también es suficiente para explicar las reglas del cómputo. El realce de la penúltima sílaba provoca que los sonidos subsiguientes se debiliten de manera que las dos sílabas átonas de los esdrújulos se perciban como una sola, pero exige en todo caso una depresión de contraste que en el caso de los finales agudos sería un silencio; en este caso, el silencio es efecto del final agudo (la relajación subsiguiente a un momento de concentración de fuerzas), y entraría, sólo en estos casos, en el cómputo silábico del propio verso y en su figura rítmica, en vez de ser un corte o una marca de separación. En este sentido, Juan Manuel Sosa (1999: 105), que no entra en cuestiones de métrica poética, considera que en la descripción de los tonemas del español es más coherente interpretar que el tono de juntura bajo, característico de los finales, se reduce fonéticamente (lo que explicaría el cómputo de los finales esdrújulos) pero se da de manera sistemática y no sólo cuando hay sílabas inacentuadas después del núcleo (lo que explicaría el cómputo de los finales agudos). Por otra parte en la percepción de todos los finales de verso como llanos ayudaría la propia estructura de la palabra castellana, que suele ser llana de manera abrumadoramente predominante, de modo que el oído tiende a introducir en ese molde las secuencias en que la estructura silábica queda destacada, como son los finales del verso.

Lo importante, en suma, es que el final del verso no suponga una solución de continuidad, que la entonación natural no se interrumpa en cada verso para volver a empezar desde cero en el verso siguiente. Esto último sería totalmente incoherente en el caso de los encabalgamientos y anómalo en todos los enlaces en que no se produzca esticomitia, y aun en los casos de esticomitia continuada tampoco es necesaria ni elegante una pausa en todos los versos que produciría igualmente ese mencionado efecto de rengloneo.

En la misma línea de lo que había dicho a propósito de los finales de grupo melódico, pero ahora refiriéndose explícitamente a la métrica poética, Navarro Tomás considera que la pausa es esencial como ele- 
mento determinante de la extensión y unidad del verso, pero afirma que tal pausa «puede consistir en una efectiva interrupción más o menos larga, según señale terminación de hemistiquio, verso, semiestrofa o estrofa, o bien puede reducirse a una simple depresión elocutiva en los puntos de división de tales unidades» (1974: 40, subrayado mío).

Creo que las palabras de Navarro Tomás, aun siendo ambiguas por lo que se refiere al concepto de pausa, son también reveladoras y merecen reflexión. Su concepto de pausa es ambiguo, en efecto, porque puede significar tanto «interrupción más o menos larga» como «simple depresión elocutiva». Es decir, en estas posiciones, aunque la que ahora nos interesa es la de final de verso que incluye también las de semiestrofa y estrofa, se produce un fenómeno fónico relacionado con el relieve de la última sílaba acentuada. Este fenómeno afecta a la división de la secuencia lingüística, de extensión indefinida, en grupos fónicos o melódicos menores. Esta división tiene como objetivo la distinción de los grupos fónicos, pero no necesariamente introducir una separación entre ellos, que sólo es conveniente cuando hay también un cambio en el curso de la sintaxis y del sentido. De ahí que, musicalmente, la división pueda hacerse por medio de una depresión elocutiva (o un tonema de juntura) o bien por una verdadera pausa (o interrupción efectiva y voluntaria del flujo sonoro). Pero esta última, sólo en el caso de que concurra también el final de un período sintácticosemántico. El verso constituye un grupo melódico que se ensambla, con mayor o menor naturalidad, en la sucesión de los grupos fónicos convencionales, de manera que cada final de verso se presenta como un final de grupo fónico. El tonema de juntura marca tanto su distinción del grupo que le sigue, lo que permite apreciar el ritmo, como su relación de continuidad con él en una unidad superior, la melodía. Y no constituye una pausa, aunque se pueda percibir como tal, pues, como indican Nespor y Vogel (1994: 39), «lo que se percibe como una pausa puede en realidad corresponder fonéticamente a una diversidad de fenómenos, entre los que se cuentan los cambios en la altura tonal [ingl. "Pitch"] y la duración, sólo en ocasiones correspondientes a un cese completo de la fonación» ${ }^{4}$. Esta circunstancia explica la utilización del

${ }^{4}$ Creo que las tesis de J. M. Sosa acerca del tono de juntura corroboran esta idea. El tono de juntura bajo se manifiesta generalmente como un descenso tonal, si bien no siempre marcado o extenso, pues se utiliza a final de enunciado, donde las sílabas tienden a ser relajadas, con el tempo y la intensidad progresivamente decrecientes (como en el final del verso). «El hecho de que a veces el efecto del tono de juntura bajo no sea claramente perceptible al oído o visible en las curvas tonales, como en ciertos enunciados muy cortos, no significa que no se halle presente». 
término «pausa» para referirse de manera indiscriminada a las variadas circunstancias melódicas que pueden producirse a final de verso ${ }^{5}$.

En definitiva, el final del verso no exige necesariamente una pausa, es decir una interrupción sensible de la dicción, pues otros fenómenos garantizan la perceptibilidad de la secuencia rítmico-silábica. Sin embargo, el final del verso es el lugar natural de las pausas que ha de haber en toda secuencia lingüística de cierta extensión, pues es la única posición en la que la pausa no altera la percepción del verso en cuanto compuesto por un determinado número de sílabas. El silencio no cuenta como parte cuantitativa del verso (como si tuviera una o dos sílabas más), sino como un vacío entre dos secuencias silábicas que se perciben y se relacionan en su constitución y tamaño propios. No ocurriría lo mismo, como ya hemos visto, con las pausas internas; éstas producirían una segmentación de grupos silábicos en colisión con la segmentación métrica de los versos, razón por la cual han quedado descartadas. Las pausas a final de verso se producirán, como interrupciones claramente perceptibles, cuando estén justificadas por la sintaxis y el sentido, es decir, han de coincidir con el final de una frase o de un período $y$, por tanto, de una curva de entonación o frase musical. Son, principalmente, las pausas que, además de coincidir con el final de un verso, coinciden con la terminación de una semiestrofa o de una estrofa.

3.4. Por último, no es posible dejar de aludir a los versos compuestos, divididos en dos hemistiquios por la cesura que, a efectos de cómputo silábico, se comporta como final de verso: impide la sinalefa, suma sílaba en los agudos y resta en los esdrújulos. El problema fundamental se encuentra en el hecho de que la cesura no tiene una marca distintiva propia (como la tiene el final del verso en el corte anticipado de la línea) y, por tanto, la entonación y la división en grupos fónicos habría de estar marcada por el sentido para que fuera perceptible por el lector. Como esta circunstancia no se produce en numerosos versos de autores clásicos, habría que suponer una competencia especializada para ejecutar correctamente estos versos compuestos, es decir, para dar el relieve preciso a la sílaba penúltima del primer grupo, que incluso podría ser átona en la lengua y recibir el acento únicamente por

5 En este sentido, es decir, entendiendo por «pausa» la interrupción voluntaria de la dicción o, lo que es más frecuente, los mencionados tonos de juntura, me parece totalmente válida la afirmación con que Domínguez Caparrós (1993:109) zanja la polémica acerca del encabalgamiento: «En cualquier caso, la "pausa métrica" nunca desaparece», pues, en efecto, el final de verso supone siempre el final de un grupo melódico con estas características tonales que venimos comentando. Lo mismo puede decirse de la disminución de la pausa, que no se suprime en las buenas dicciones, a que se refiere Isabel Paraíso. 
su posición. Esteban Torre (2000:79-99) estudia con detalle todas las anomalías que presenta el alejandrino y las soluciones que se proponen, y evoca unas palabras de Leopoldo de Luis a propósito de las irregularidades del alejandrino de Juan Ramón Jiménez ${ }^{6}$ que me parecen enteramente válidas y generalizables:

«Como es obvio que nadie, en una lectura normal, marca la cesura de los versos con tan artificiosa manera, el resultado de este tratamiento del alejandrino es un ritmo ondulante, original y grato" (Luis, Prólogo a La soledad sonora, 1981: 37, en Torre, 2000: 91).

Es decir, la dicción natural no separa los grupos fónicos artificiosamente, en medio de una palabra, por ejemplo, y en general no consiente la segmentación del verso compuesto en hemistiquios a base de violentar la orientación propuesta por el sentido. Es preferible guiarse por éste y considerar el resultado como variaciones rítmicas más o menos originales y gratas.

La cesura, por último, no implica pausa, como tampoco la implican ni el final del verso ni la división interior de los versos simples, sino un realce de la última sílaba acentuada con los efectos tonales consiguientes. Este realce puede alterar el cómputo de agudas y esdrújulas e impedir la sinalefa, si coincide con una segmentación natural de los grupos melódicos ${ }^{7}$, pero plantea los problemas comentados más arriba si estos fenómenos suponen la quiebra de la entonación guiada por el sentido.

\section{EL VERSO}

El verso es el equivalente poético del compás. Fija el número de sílabas, la posición del acento principal y la condición de los acen-

6 Primer hemistiquio de seis sílabas con la última acentuada por su posición final, a pesar de ser partícula átona como artículo o preposición («la música de las / tardes primaverales») lo que no impide, en otros casos, la forma de primer hemistiquio agudo de siete sílabas que no pide la adición de otra sílaba, corte de palabra para repartirla entre los dos hemistiquios («Ah quien pudiera pro- / longar eternamente»),... Torre, 2000: 90-91.

7 Creo que esta posibilidad se funda en que el tamaño de los hemistiquios los convierte en grupos melódicos más consistentes que los grupos más breves que resultan de dividir los versos simples. 
tos secundarios. Los teóricos hablan, en este sentido, de modelo de verso o fórmula repetible con ciertas variaciones posibles. Los versos concretos de los poemas realizan esas fórmulas («ni cuando las noches son»: :«en que el mentido robador de Europa»: :«Salinas, cuando suena»: :«e los ricos» son versos de conocidos poemas hispánicos).

Aunque, como veremos en el epígrafe siguiente, la musicalidad del poema se refiere a la totalidad de la composición, el verso contribuye a ella precisamente por sus condiciones estables, es decir por obedecer a principios de obligado cumplimiento que determinan no sólo el ritmo, sino también la melodía, mejor dicho, animan la melodía mediante el ritmo.

Como ya queda señalado, el principio básico de todos los versos clásicos es su acentuación principal en la penúltima sílaba; debido a que la acentuación misma implica la alternancia de sílabas átonas y tónicas, este principio básico define por extensión como posiciones aptas para recibir acentos rítmicos a todas las posiciones pares de los versos de número de sílabas impar y a todos los impares de los de número par. Si esta circunstancia se explota y enfatiza puede producir un ritmo continuado de átona-tónica-átona-tónica-atona-tónica en el que se despreciaría la última sílaba. Pero, como decimos, esto exige un empleo sistemático de esta alternancia (u otra similar, como la dactílica del hexámetro) y una dicción enfática que no responden a los hábitos espontáneos del hablante ni a las características del idioma. El acento no es cuestión de intensidad, sus efectos acústicos no se concentran en la sílaba acentuada ni todas las sílabas acentuadas tienen el mismo «relieve»; por ello, resulta artificial y excesivamente mecánica una elocución que subraye todas las sílabas tónicas, aunque a veces se busque un ritmo de este tipo y en general actúe como un complemento rítmico que se percibe de fondo y no en el primer plano, si presenta cierta regularidad.

La variación del relieve relativo del acento y, por tanto, su participación en el trazado de la curva melódica, que se superpone a su contribución rítmica, queda bien explicado si se considera, como hacen I. Nespor y M. Vogel (1994) apoyándose en ideas de Carlos Piera, que los componentes del verso se integran en una jerarquía métrica: las sílabas forman pies métricos (grupos de átona-tónica), los pies métricos se agrupan en un colon (constituido por dos o más pies) y los cola en versos. Así, los endecasílabos podrán representarse de la siguiente manera (Nespor y Vogel, 1994: 317): 


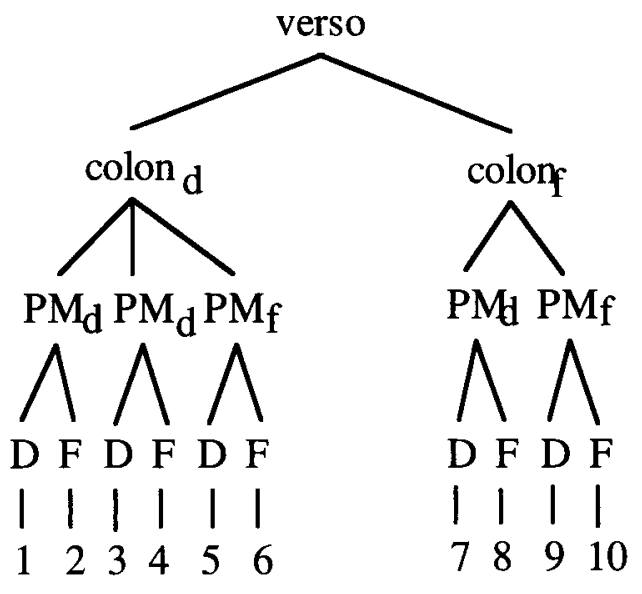

o bien de esta otra

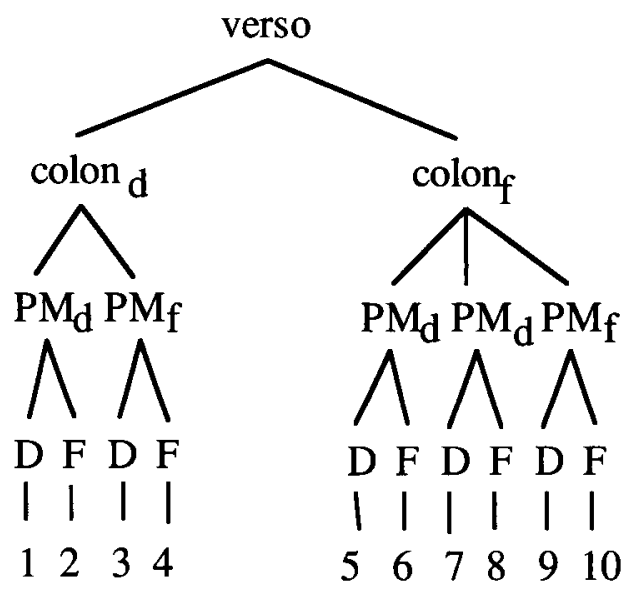

Las unidades de la izquierda (tanto en las sílabas, como en los pies, y los cola) están caracterizadas como débiles, frente a las de la derecha, que son las fuertes (la posición que sigue a la décima queda excluida como extramétrica). La introducción del constituyente colon y la jerarquía métrica en general, permite distinguir varios niveles de definición de la sílaba tónica: en cuantos más niveles participe y cuanto más a la derecha lo haga, mayor significación tendrá; así, la décima sílaba queda destacada por ocupar el lugar más a la derecha y formar parte del pie, del colon y del verso; por el contrario, la sílaba primera es la de menos relieve, por ocupar la posición más a la izquierda y, por 
tanto, tener escasa participación en la definición del colon y del verso. Las sílabas que siguen en importancia a la décima son la cuarta o la sexta, porque ocupan el lugar más a la derecha del colon de la izquierda. Este esquema define el ritmo y es la base para la curva melódica del verso. Sobre él pueden hacerse variaciones acentuando posiciones débiles (como el endecasílabo enfático, que lleva acento en primera): acentos equivalentes a los marcados explícitamente en las partituras musicales, en este caso por la acentuación predeterminada de la palabra. Sin embargo, estas variaciones no pueden afectar a la posición fuerte del colon (en el endecasílabo, la cuarta o la sexta y la décima) sin alterar la orientación rítmica y, por tanto la naturaleza del verso. Un endecasílabo galaico antiguo, con acento en la quinta, es un metro distinto del endecasílabo tradicional y sólo puede aparecer en un poema en el que estos predominen como una desviación que busca determinado efecto.

«Cantar es hablar despacio para saborear los matices», afirma McLuhan (1972: 278); D'Introno lo dice al revés «Hablar una lengua no implica solamente concatenar sonidos, morfemas y palabras en oraciones y entender el significado de cada palabra morfema u oración formada, implica también cantar en esa lengua: al decir una oración el hablante no sólo articula los sonidos consonánticos y vocálicos contenidos en la oración, también le asigna a la oración una melodía y un ritmo» (1999: 13). Hablar es cantar, cantar es hablar...despacio. La poesía no hace sino enfatizar (despacio...) y sistematizar lo que es una tendencia natural de la lengua (el ritmo, tan vinculado a la función poética: recuérdense en este sentido las reflexiones de Jakobson según las cuales el hablante prefiere inconscientemente por principios rítmicos ciertas secuencias como «Juana y Margarita» a sus equivalentes menos rítmicas como «Margarita y Juana»). La sistematización la encontramos en el artificio métrico que construye el ritmo a partir del verso y del relieve de su penúltima sílaba. La enfatización, el saborear los matices, procede de una dicción atenta y cuidada, pero natural, en la que se revelan los perfiles de la jerarquía métrica (pies, cola, verso).

Ahora bien, la jerarquía métrica, puesto que no existen notaciones especiales salvo la del final del verso, sólo puede basarse en la dicción natural y, por lo tanto, en el sentido. Por ejemplo, será el sentido del enunciado el que determine en el endecasílabo si el primer colon consta de dos o tres pies métricos. En este sentido la jerarquía métrica es claramente rítmica en la medida en que se apoya en la posición de determinadas sílabas acentuadas (cuarta o sexta y décima, en el 
endecasílabo); pero al mismo tiempo anuncia ya la melodía, pues el sentido se realiza no en una sucesión de golpes más o menos fuertes (sílabas acentuadas e inacentuadas), sino en una sucesión de tonos de distinta altura, cuyos altibajos configuran la entonación de los enunciados, es decir su melodía.

\section{MÁS ALLÁ DEL VERSO}

El verso se agrupa en estrofas, que configuran modelos cerrados de composición, diríase incluso que de composición musical; el flujo lingüístico se ajusta a estos moldes proporcionados que obligan a que la melodía se detenga en un punto. Porque más allá del verso se desarrolla la música. Hemos visto cómo los elementos rítmicos, al ser más o menos fijos, se extienden por todo el poema; por el contrario, los elementos melódicos, porque nacen del sentido del enunciado y se manifiestan en las diferencias entre unidades (sílabas sucesivas, más o menos altas), parecen concentrarse en el verso. Pero, en realidad ocurre al revés, los elementos rítmicos se dan en el verso, de manera reiterada, es decir en cada verso, pues desde el punto de vista métrico-rítmico todos los versos son iguales o muy semejantes. La melodía, en cambio, se extiende más allá del verso, porque el sentido no termina necesariamente con la última sílaba de éste. Si una frase interrogativa, por ejemplo, ocupa tres versos, su curva melódica, los ascensos y descensos del tono característicos de la interrogación más sus incisos y ramificaciones se suceden de un verso a otro, con la anomalía sistemática producida por el axis rítmico de final de verso, que puede ir acompañado de un tonema de suspensión pero no de pausa significativa, salvo cuando concurre el silencio natural de período melódico (en posición relevante de la estrofa).

La entonación de las frases, más que de los versos, está regida por el sentido de las mismas, aunque no coincide exactamente con el sentido, pues este debe mucho al significado convencional de los vocablos y de las estructuras gramaticales. Pero, como señala D'Introno en su breve pero sugestiva Introducción al libro de J. M. Sosa, se puede extraer la melodía de la oración, por ejemplo expresándola con el silbido, sin usar vocales y consonantes. La diferencia entre el sentido de las melodías se reconoce independientemente del nivel de competencia linguística, pues se apoya en el carácter motivado que poseen los 
signos paralingüísticos. Es lo que ocurre en la música: en las melodías reconocemos una intención significativa, un querer decir algo que, por no estar codificado en signos lógicos y convencionales, no puede traducirse en categorías lingüísticas ni expresarse fuera de la música misma. Por eso la melodía, que se desarrolla indefinidamente, se manifiesta en temas, es decir en unidades de contenido, aunque en música se trate de contenido no conceptual o muy difícilmente conceptualizable. Pero los límites de los temas musicales no coinciden exactamente con los límites de los compases, aunque frecuentemente sí coincida su final. Pues bien, lo mismo podemos decir de la poesía. La melodía, animada por el ritmo y la regularidad del verso, se proyecta de acuerdo con el sentido en los versos siguientes en una sucesión cuyas interrupciones no pueden ser más que interrupciones del sentido manifestado musicalmente, es decir en la línea de altitudes que forma la melodía. El verso, decían los formalistas rusos a propósito del poema, es un discurso organizado en su trama fónica total: el metro, es decir el tipo de verso, es el mecanismo de organización, no la medida de segmentos autónomos con valor propio, por más que muchos versos sueltos resulten felices expresiones poéticas. La noción de trama fónica total, la idea de totalidad que se despliega linealmente subraya precisamente el carácter que el poema tiene de composición musical, de sucesión de sonidos que se imponen por sí mismos formando un todo que resulta satisfactorio en la medida en que es expresivo o significativo. Es decir, la melodía no sólo es un resultado del sentido, sino que sólo se percibe como melodía en cuanto se capta en ella ese querer decir algo que, en definitiva dice, pues en el caso de la música el sentido no es formulable conceptualmente, queda dicho en la forma musical, y, en el caso de la poesía, la entonación es inseparable de las unidades lingüísticas convencionales, cuyo contenido transforma e incrementa con valores musicales, es decir, no conceptuales.

En resumen, la musicalidad del poema se encuentra en su desarrollo melódico que se pliega rítmicamente al esquema métrico adoptado. Es esta incrustación en los moldes rítmicos del verso lo que define a la melodía poética: las elevaciones y depresiones en la altura tonal, en definitiva, están en relación con el sentido del enunciado, en la medida en que éste determina la división en grupos de entonación y la decisión de cuáles son, dentro de éstos, las sílabas acentuadas y las sílabas inacentuadas y de cuáles de las acentuadas (y las adyacentes inacentuadas) están asociadas a cambios tonales y cuáles no (Sosa, 1999: 33). El verso, es decir, el esquema rítmico, introduce un elemento de distorsión en el flujo natural de los tonos en la medida en que supone una 
división artificial (al margen del sentido) de los grupos de entonación y, como consecuencia de ello, una asignación artificial de acentos de grupo. Por ello, la línea melódica del poema se mueve gradual y cadenciosamente, es decir con constantes subidas y bajadas en el tono, pero generalmente sin grandes saltos, siguiendo simultáneamente el curso del sentido, de ese querer decir que la define, y el curso del verso, de esa división y acentuación arbitrariamente regular que una veces converge y otras entra en conflicto con el curso sintáctico semántico, pero que en la dicción han de quedar en todo caso ensamblados sin violencia.

\section{EL VERSO LIBRE}

No es mi propósito prestar atención especial al verso libre, pues en lo que afecta a su naturaleza musical y a su ejecución se habrá de regir por los mismos principios que todo verso: relieve especial de la penúltima sílaba que delimita su unidad y, por lo demás, entonación natural. El problema del verso libre, a mi entender, se refiere al ritmo, a la regularidad y a la equivalencia de ciertas unidades. La penúltima sílaba de un verso clásico es equivalente a la de todos los demás versos del poema por su especial relieve, pero además ocupa siempre o bien la misma posición (si todos los versos son del mismo tipo) o bien posiciones relacionadas (si los versos son de distinto tipo y tamaño: sexta y décima, por ejemplo, en la lira, que combina endecasílabos y heptasílabos). En el verso libre, el cómputo silábico desaparece o está enmascarado o muy atenuado. Esto no impide que la penúltima sílaba constituya un acontecimiento que se debe subrayar, pues es este acontecimiento el que hace de la línea un verso, esto es una unidad que entra en correlación con las demás unidades de la misma naturaleza para formar una composición rítmico musical. Frente a la relación de igualdad o proporción en la cantidad de sílabas que constituyen cada unidad en el verso clásico, el verso libre utiliza otros tipos de relación menos definidos y, sobre todo, menos exactos. Las estructuras sintácticas, las cláusulas acentuales, el tamaño silábico aproximado son, entre otros, los factores de repetición que permiten seguir hablando de ritmo y de verso, por tanto de una música que apoya su melodía en el especial relieve de la penúltima sílaba de cada unidad: los matices particulares que puedan producir otros motivos (ritmos aliterantes, cláusulas, 
repeticiones léxicas y gramaticales) lo hacen dentro de la entonación característica de la poesía métrica que se define por la división artificial en versos y del ritmo que genera la relación de unos con otros, como totalidades sonoras que se constituyen partir del énfasis de su final. Si no se da esta relación, o bien es que se ha abandonado el propósito musical y se ha orientado la composición por otros derroteros, o bien el verso libre no es sino una prosa rítmica, que apoya su musicalidad en las repeticiones mecánicas inherentes a la producción del habla con ciertos refuerzos expresivos. Si el poema sigue, aunque sea de manera relajada, principios métricos, las directrices para su ejecución son las que afectan a toda composición en verso: la presentación sobre la página que enfatiza la penúltima sílaba de cada línea y, por lo demás, entonación siguiendo el sentido.

\section{LA LECTURA DEL POEMA}

El concepto de lectura tiene dos sentidos, en algún aspecto divergentes, que en la poesía, sin embargo, han de conciliarse para alcanzar la densidad expresiva que le es característica. Leer es, por un lado, pronunciar lo que está escrito o impreso ante nuestra vista, $y$, por otro, es captar o comprender el significado de lo que está escrito, aunque no lo pronunciemos. Se puede pronunciar sin captar (si desconocemos el significado de los términos) y se puede captar y comprender sin pronunciar (reconociendo visualmente los caracteres). En cierto modo, esto último constituye el objetivo último del aprendizaje de la lectura: superar la rigidez del silabeo y más tarde de la pronunciación para avanzar con cierta rapidez sobre las palabras y las líneas. Se lee, entonces, reconociendo visualmente las palabras, sin reparar excesivamente en el sonido, que no es necesario para atribuirles una significación. Pero la poesía, sin desdeñar del todo las relaciones convencionales de significación, vuelve a los orígenes del lenguaje, al sonido pronunciado como agente de toda significación. No es sólo la cuantificación métrica lo que entra en juego, también la cualidad de los sonidos mismos, sus combinaciones y repeticiones próximas (aliteración) y distantes (rimas y ecos) y hasta los paralelismos sintácticos que, como bien ha analizado $S$. R. Levin, convergen frecuentemente con equivalencias fónicas y, desde luego, con equivalencias tonales. Pero la organización métrica tiene especial importancia porque, antes que cualquier 
efecto particular de los sonidos, sirve para conservarlos y enfatizarlos, para que la significación convencional no haga que se desvanezcan y puedan mostrar sus valores propios, en cuanto sonidos (agrupados musicalmente), y no sólo en cuanto signos. Por esto mismo, la lectura de un poema, sin ser artificiosa, ha de ser muy cuidada.

El poema es un organismo complejo, sus resortes rítmicos y melódicos, sus convenciones de cómputos (sinalefas, hiatos,...), sus matices y sus arabescos, sin desobedecer en esencia al sistema lingüístico, tampoco son consecuencia de su aplicación mecánica, pues dependen de los modelos de verso y de estrofa elegidos y de la adopción de alguna de sus diversas posibilidades. Una lectura improvisada puede tropezar, seguir caminos equivocados (al elegir los acentos más relevantes, por ejemplo), iniciar una curva melódica incorrecta, etc. Como el ejecutante musical, que difícilmente alcanza una buena versión de la pieza cuando la ejecuta por primera vez sin haberla analizado antes, el lector de poesía debe hacer lecturas de preparación y tanteo, con correcciones y ajustes, hasta alcanzar una ejecución continuada y satisfactoria. En general, se requiere un equilibrio entre una dicción natural que no resulte, sin embargo, atropellada, y una sujeción a las convenciones métricas, que reduzca las tensiones y violencias, como en los encabalgamientos, y no caiga en la afectación. Este difícil equilibrio supone una dicción clara y precisa, pero sin parsimonia ni precipitación: las sílabas han de distinguirse, pues son la unidad de cómputo cuya medida nos hace reconocer el ritmo del poema, pero no como entidades separadas, sino dentro de la palabra y de la frase. Y lo mismo vale para los versos: el oído debe sentirlos, pero no como golpes autónomos, sino dentro del decurso, de la trama fónica total, más que sentir los versos, sentir el ritmo que se consigue por la repetición del axis a intervalos regulares.

Ya hemos discutido los problemas que supone la delimitación del verso y la tradicional exigencia de una pausa como factor de demarcación. Baste ahora insistir en que tal pausa, de existir, no puede consistir en un silencio prolongado, que suponga un corte, sino una levísima suspensión. Las recitaciones anómalas muestran la necesidad del equilibrio. En efecto, tales anomalías, consisten, por un lado, en hacer una pausa demasiado larga que destaca al verso como entidad separada, de manera que se pierde la musicalidad secuencial y, en casos de encabalgamiento incluso suave, se produce una violencia excesiva entre la entonación y el sentido e incluso una entonación antinatural, pues la frase queda cortada de improviso. Si, por el contrario, no se hace pausa alguna ni se enfatiza el final del verso, la sucesión se siente como 
prosa. La solución es, como ya se ha repetido, una levísima pausa que más que una interrupción es un efecto tonal de suspensión que permite mantener unidos en la curva melódica los versos sucesivos y apreciar al mismo tiempo la regularidad y el ritmo. La melodía dibuja su curva: al final del verso esa curva se caracteriza por una elevación y depresión subsiguiente. Esta depresión puede ir seguida de pausa, si el sentido lo requiere, o adoptar la forma de un efecto tonal, apenas perceptible a veces, pero, en todo caso, claramente diferente de una interrupción efectiva.

Sin duda, como ya señalamos al comienzo del artículo, la naturaleza sensorial de la poesía, el hecho de que se manifieste en la sonoridad de los signos lingüísticos, entra en conflicto con la recepción visual que impone la tecnología de la imprenta. La poesía, tanto la creación como la recepción, desde el momento en que tiene como soporte el libro y da prioridad al sentido de la vista sobre el del oído, corre el riesgo de reforzar su aspecto intelectual y reflexivo, y perder su oralidad y musicalidad constitutiva. La puntuación, por ejemplo, refuerza una segmentación conceptual del discurso y una entonación analítica, que no conviene a la poesía.

Ahora bien, la poesía se ha desarrollado ampliamente en la galaxia Gutenberg; quizá en muchos casos con una hipertrofia del contenido reflexivo y una observancia de la métrica más mecánica que como una promoción de su música y su oralidad, pero en general los grandes poetas han conservado la conciencia del carácter sonoro de su creación. Han utilizado la página del libro como vehículo de comunicación, pero han buscado fórmulas que orientasen la dicción musical. La propia disposición tipográfica de la poesía, diferente de la disposición de los demás textos, destaca la regularidad, la repetición de sílabas, la unidad musical formada por el verso y, en suma, el ritmo del conjunto. Ya hemos dicho que la puntuación impone en exceso la estructura lógica del discurso. Sin embargo, también puede ser utilizada como un regulador del tempo de lectura, especialmente si, en vez de seguir las convenciones sintácticas, asume sus propios criterios. Baste como ejemplo el siguiente poema de Dámaso Alonso:

\section{EL DESCANSO}

He aquí la calma del hogar lejano, el manso río, el otoñal paisaje.

(Ay, solitario y lento peregrino, ¡descansa ya!

Su mano 
borrará de tu traje

la polvorienta huella del camino.)

Pisaba ya el umbral.

- Hogar.

Y sonreía.

Paisaje.

Otoño.

Río manso.-

Y en el reloj del muro el Sol ponía

la irreparable hora del verano.

Las rimas indican con toda claridad que el poema consta de 10 versos (...lejano, ...paisaje, ...peregrino, ...mano, ...traje, ...camino, ...sonreía, ...manso, ...ponía, ...descanso). En el interior de los versos 4, 7 y 8 hay puntos y aparte; sin embargo no han de ir seguidos de pausa, pues ésta interrumpiría el flujo melódico y alteraría la medida del poema, especialmente en el verso 8 , un endecasílabo que tendría hasta cuatro pausas. Pero esos signos tipográficos modulan la curva melódica (no es exactamente la misma entonación que si fuesen separados por comas) en la medida en que afectan al tempo elocutivo, más lento debido tanto al punto como a la caída visual. Es decir, el punto y aparte equivale a una notación musical del tipo «rallentando», «ritardando», etc., que no afecta al ritmo base. En todo caso, es difícil establecer reglas que asignen a formas concretas este tipo de efectos que dependen no sólo de la puntuación (o su ausencia, que apunta a una dicción más rápida) y de los efectos tipográficos, sino también del tamaño del verso, de las estructuras sintácticas y de la propia significación del poema. Pero tales efectos, que el poeta codifica en la medida en que él mismo los experimenta, no son sino variaciones que se someten a la entonación natural musicalizada por la regularidad métrica ${ }^{8}$.

El poema, en fin, se realiza plenamente no tanto en el acto de lectura, como en la dicción, que no tiene que ser necesariamente consecuencia de la lectura, aunque esto sea lo más frecuente, especialmente desde que la poesía tiene como vehículo el libro. Pero leer, como ya se ha repetido varias veces, es una actividad muy relacionada con las teconologías de la escritura que en nada favorecen la oralidad y la

8 Lo mismo puede decirse de la ausencia de puntuación. Otros artificios tipográficos, como el tamaño de las letras, la poesía concreta y los caligramas, aun subrayando y explotando el carácter visual de la página, no desdeñan necesariamente la sonoridad del poema, y si bien resulta imposible leer muchos de estos poemas en voz alta, tampoco pueden asimilarse sin cierta presencia interna del sonido articulado (Vid. Ong, 1987: 128). En todo caso, merecen una consideración más detenida que nos obliga ahora a dejarlos al margen. 
musicalidad de la poesía, por el contrario, hacen prevalecer lo visual sobre lo acústico, promueven la reflexión y el análisis en lugar del canto y, en el caso de realización oral, suscitan una dicción más lógica y analítica que rítmica y melodiosa. La presentación sobre la página, con el corte anticipado de la línea, es el único recurso tradicional para imponer una entonación musical que obedezca a las leyes del ritmo y sólo en segundo término a las de la sintaxis. La entonación musical se produce también en la lectura para uno mismo, pues tiene una representación interior en los movimientos musculares y respiratorios característicos de la subvocalización, promovida, precisamente, por la organización métrica del texto, y en la consecuente exigencia de tener presentes todos los sonidos, sílaba a sílaba, en lugar de asimilarlos globalmente en una aprehensión meramente visual.

Pero ese corte anticipado de la línea, equivalente a la barra de compás en música, se entiende muchas veces como una pausa, como una detención voluntaria y, por tanto, relativamente prolongada de la dicción. El resultado suele ser una recitación que separa los versos y rompe la continuidad melódica. Sin embargo, son las elevaciones y depresiones tonales, agrupadas en forma de motivos y de temas, las que con sus desarrollos, variaciones y repeticiones trazan el perfil melódico que trasciende el verso y abarca la composición en su conjunto.

Esta presencia del sonido y su musicalización dota a la palabra, a la frase y al texto poético de concreción, pues es una palabra dicha en una situación única, y conforma una espesura de significantes: no sólo el signo convencional, sino los signos concomitantes del paralenguaje y de la gestualidad necesaria para su realización. De esta manera son doblemente profundos: tienen una significación densa, por la complejidad de los elementos significantes, y surgen del interior del lector, de su energía fonatoria, implicándolo en su propia constitución.

\section{Referencias bibliográficas}

D'INTRONo, F. (1999). «Presentación» a Sosa, J. M. (1999).

Domínguez Caparrós, J. (1993). Métrica española. Madrid: Síntesis.

MARTÍnez CeldRÁn, E. (1986). Fonética. Barcelona: Teide.

MCLuHAN, M. (1972). La galaxia Gutenberg. Génesis del homo typographicus, Aguilar, Madrid. Trad. De The Gutenberg Galaxy. University of Toronto Press, 1967. 
Navarro Tomás, T. (1974). Métrica española. Barcelona: Guadarrama.

NesPor, M. y Vogel, Y. (1994): La prosodia, de. Visor, Madrid. Trad. De Prosodic Phonology. Dordrecht: Foris Publications, 1986.

ONG, W. (1987): Oralidad y escritura. Tecnologías de la palabra, F.C.E., México. Trad. De Orality and Literacy. The technologizing of the Word. Londres: Methuen \& Co Ltd., 1982.

PARAf́so, Y. (2000): La métrica española en su contexto románico. Madrid: Arco/Libros.

SosA, J. M. (1999). La entonación del español. Madrid: Cátedra.

Torre, E. (2000). El ritmo del verso. Murcia: Servicio de Publicaciones de la Universidad de Murcia. 